\title{
Article \\ A Comparative Study of Energy Efficiency in Tumbling Mills with the Use of Relo Grinding Media
}

\author{
Nikolay Kolev ${ }^{1}$, Petar Bodurov ${ }^{1}$, Vassil Genchev ${ }^{1,+}{ }^{+}$, Ben Simpson ${ }^{2}$, Manuel G. Melero ${ }^{3}$ and \\ Juan M. Menéndez-Aguado $4, *$ (D) \\ 1 Relo-B Ltd., 1463 Sofia, Bulgaria; nicolai.kolev@mail.bg (N.K.); pbodurov@mgu.bg (P.B.); \\ vassil.genchev@digitalprint.bg (V.G.) \\ 2 Wardell Armstrong International Ltd., Truro TR3 6EH, UK; bsimpson@wardell-armstrong.com \\ 3 Departamento de Ingeniería Eléctrica, Electrónica, de Computadores y Sistemas, Universidad de Oviedo, \\ 33203 Gijón, Spain; melero@uniovi.es \\ 4 Escuela Politécnica de Mieres, Universidad de Oviedo, 33600 Mieres, Spain \\ * Correspondence: maguado@uniovi.es; Tel.: +34-985458033 \\ $\dagger$ In memory of V. Genchev.
}

check for updates

Citation: Kolev, N.; Bodurov, P.; Genchev, V.; Simpson, B.; Melero, M.G.; Menéndez-Aguado, J.M. A Comparative Study of Energy Efficiency in Tumbling Mills with the Use of Relo Grinding Media. Metals 2021, 11, 735. https://doi.org/ $10.3390 /$ met11050735

Academic Editors: Leszek Adam Dobrzanski and Luis Norberto López De Lacalle

Received: 5 March 2021

Accepted: 27 April 2021

Published: 29 April 2021

Publisher's Note: MDPI stays neutral with regard to jurisdictional claims in published maps and institutional affiliations.

Copyright: (c) 2021 by the authors. Licensee MDPI, Basel, Switzerland. This article is an open access article distributed under the terms and conditions of the Creative Commons Attribution (CC BY) license (https:/ / creativecommons.org/licenses/by/ $4.0 /)$.

\begin{abstract}
An evaluation of Relo grinding media (RGM, Reuleaux tetrahedron-shaped bodies) performance versus standard grinding media (balls) was made through a series of grinding tests, including a slight modification of the standard Bond test procedure. Standard Bond tests showed a reduction in the Bond ball mill work index $\left(w_{i}\right)$ of the mineral sample used in this study when using Relo grinding media. The modified Bond test procedure is based on using the standard Bond ball work index test but changing the circulating loads $(350 \%, 250 \%, 150 \%, 100 \%)$. The comparative tests with RGM were carried out at the same number of revolutions as the grinding tests with balls at respective circulating load. The RGM charge yielded a 14\% higher net undersize product than balls, which hints at improving energy efficiency and the potential for significant mining industry benefits.
\end{abstract}

Keywords: comminution; ball mills; grinding media; energy efficiency

\section{Introduction}

Energy efficiency in the mining industry is an ever-growing concern for sustainable mineral processing and the life of mine activities. Prior to beneficiation, the ore must pass through various stages of comminution, the process in which the particle size of the ore is progressively reduced until mineral particles have been liberated. Comminution operations, including grinding, consume up to $4 \%$ of electrical energy globally, and about $50 \%$ of mine site energy consumption is in comminution [1-6]. A study shows that the grinding process alone contributes to approximately $40 \%$ of all power consumption in a mine complex [7]. Tumbling mills are notorious for their low energy efficiency because they only use up to $10 \%$ of installed power for grinding action. A feature of ball mills is their high specific energy consumption; a mill filled with balls, working idle, consumes approximately as much energy as at full-scale capacity, i.e., during the grinding of material. Radziszewski [8] showed that $56 \%$ of the input energy in grinding circuits becomes heat lost to the environment; $43 \%$ is lost in heating the slurry, while only $1 \%$ is actual breakage energy. A recent and more comprehensive study has shown that, on average, $79 \%$ of the supplied electrical energy converts to heat absorbed by the slurry, $8 \%$ is lost through the drive system; about $2 \%$ of the energy is transmitted to ambient air, and just about $10 \%$ is used for the grinding work [9]. Therefore, about $90 \%$ of the thermal energy is potentially recoverable, and there is vast potential for improvement in energy efficiency.

One way to reduce energy and material consumption in milling is to design and select the grinding media properly. Hassanzadeh [10] argues that ball size distribution plays a significant role in energy consumption and ball mill efficiency. Larger balls break coarse 
particles mainly by impact, while smaller balls produce breakage by abrasion. Generally, for a fixed volume of grinding charge, particle-ball collision frequency falls rapidly as the ball size increases. Research about mixtures of media shapes points out that, by combining different grinding mechanisms in terms of contacts, the volume of grinding zones can be efficiently increased when there is an optimal mixture of two or more grinding media with different shapes and, therefore, the milling kinetics can be improved [11].

There have been several attempts to establish the shape of grinding media that is best suited for tumbling mills. One of the most comprehensive studies [12] concluded that the sphere is the most efficient for all shapes tested for constant batch grinding time. Kelsall et al. [13] studied the influence of different grinding media shapes (steel spheres, cubes, equi-cylinders, and hexagonal "cylinders"), and they also concluded that spherical media handled the most significant throughput and produced the most correctly sized product. Many authors compared spherical balls to cylpebs, and they concluded that balls had better grinding efficiency [14-17]. Some authors claimed that cylpebs had produced slightly more fines than balls, but no quantification of increased throughput has been made $[18,19]$. In [20], the grinding behavior of balls, eclipsoids, and cubes was investigated. In the case of eclipsoids, which have a $25 \%$ higher total surface area than balls equivalent in volume, it was found that the increase in surface area available for breakage does not necessarily translate into an increase in the breakage rate. This study concluded that balls proved to have a higher rate of breakage, confirming that balls are the most efficient grinding media.

Although there are no quantified statements on what range of improvement in energy efficiency has been achieved for tumbling mills when changing the shape of grinding media in tumbling mills, cylpeb manufacturers claim that they deliver $25 \%$ greater grinding capacity in a typical mill charge. However, this may apply only to regrind milling circuits. Relo grinding media (RGM) [21], which are described in Section 2, seem to be suitable for a wide range of applications, including SAG mills. Moreover, in [21], a plant trial is described in which RGM increased mill throughput by $80 \%$, achieving approximately $45 \%$ lower energy consumption than balls.

This research work aims to test the performance of RGM in a laboratory mill, quantifying the differences when using RGM instead of balls.

\section{Physical Properties of Relo Grinding Media}

The introduced RGM (Figure 1) receives the name in honor of the German engineer Franz Reuleaux, a mechanical engineer, who gave his name to this geometrical shape in the nineteenth century. Although these grinding bodies come in slightly different shapes, they are all derived from Reuleaux geometry, i.e., the Reuleaux triangle and the Reuleaux tetrahedron are the base structural shapes of RGM. RGM are made of steel, including all types commonly used for making balls. Moreover, according to Penchev and Bodurov [22], due to their shape, RGM steel bodies have better quench hardening than balls at equal tempering conditions; these comparative tests were performed using equal steel $(0.65 \% \mathrm{C}$, $1.03 \% \mathrm{Mn})$. Accordingly, it seems appropriate to study the performance of RGM and see if they can offer significant efficiency improvements in tumbling mill grinding circuits.

Because of their Reuleaux geometry, an RGM charge has a greater surface area and a higher bulk density than balls with the same mass and size. Table 1 shows the comparative physical properties for RGM and balls. Ideally, RGM have a 10\% greater surface than balls of the same mass (volume) and 10\% higher bulk density than steel balls. As a result, for a given charge volume, more grinding media surface area is available for size reduction when charged with RGM, but the mill would also draw more power. 


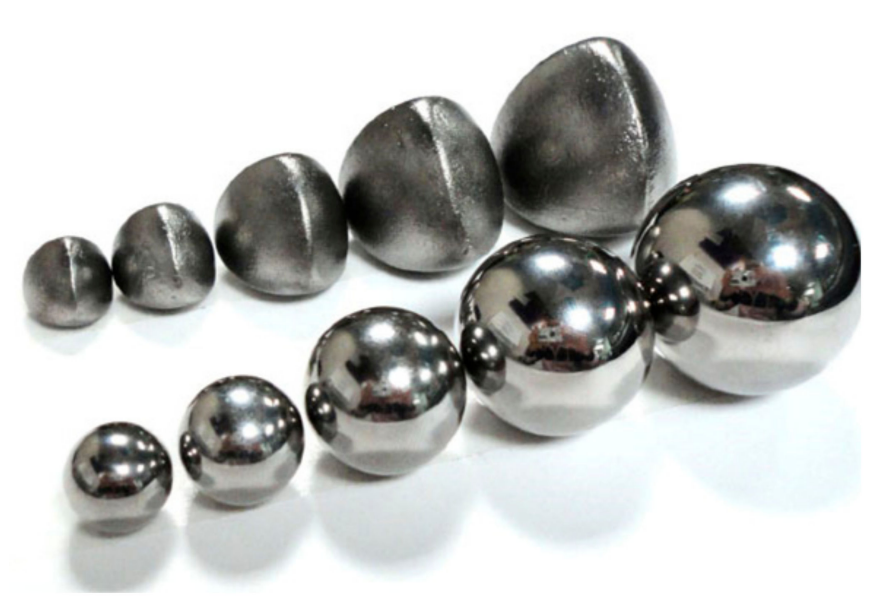

(a)

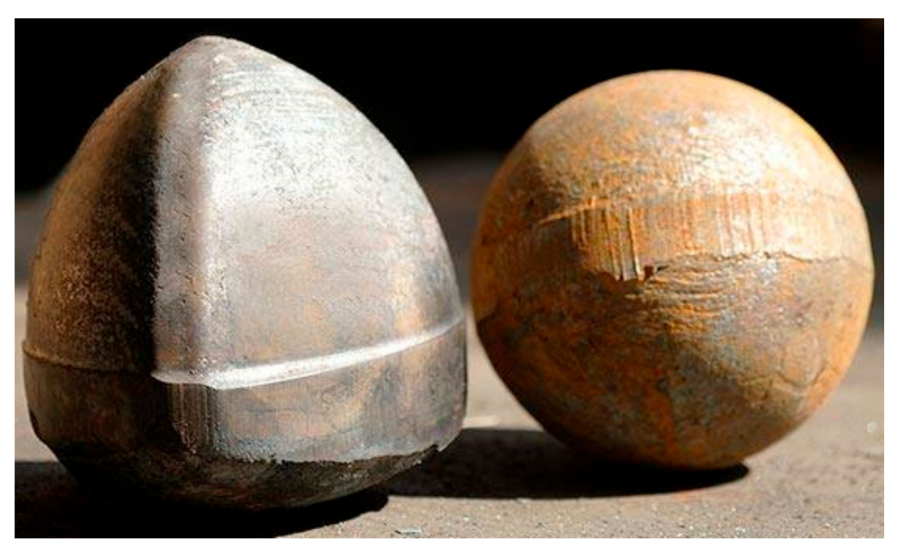

(b)

Figure 1. Grinding media charges: (a) Relo M-1 vs. balls (b) Relo M-2 vs. ball.

Table 1. Comparative data of physical properties for RGM and balls.

\begin{tabular}{|c|c|c|c|c|c|c|c|c|c|}
\hline \multicolumn{5}{|c|}{$\operatorname{RGM}\left(\gamma=7.85 \mathrm{~g} / \mathrm{cm}^{3}\right)$} & \multicolumn{5}{|c|}{ Balls $\left(\gamma=7.85 \mathrm{~g} / \mathrm{cm}^{3}\right)$} \\
\hline $\begin{array}{c}\text { Edge Arc } \\
(\mathrm{mm})\end{array}$ & Mass (g) & $\begin{array}{c}\text { Surface } \\
\text { Area }\left(\mathrm{cm}^{2}\right)\end{array}$ & $\begin{array}{l}\text { Specific } \\
\text { Surface } \\
\left(\mathrm{cm}^{2} / \mathrm{g}\right)\end{array}$ & $\begin{array}{c}\text { Bulk } \\
\text { Density } \\
\left(t / m^{3}\right)\end{array}$ & $\begin{array}{l}\text { Diameter } \\
(\mathrm{mm})\end{array}$ & Mass (g) & $\begin{array}{c}\text { Surface } \\
\text { Area }\left(\mathrm{cm}^{2}\right)\end{array}$ & $\begin{array}{l}\text { Specific } \\
\text { Surface } \\
\left(\mathrm{cm}^{2} / \mathrm{g}\right)\end{array}$ & $\begin{array}{c}\text { Bulk } \\
\text { Density } \\
\left(t / m^{3}\right)\end{array}$ \\
\hline 41.4 & 235 & 51 & 0.22 & 5.2 & & & & & \\
\hline 40.2 & 212 & 48.1 & 0.23 & 5.2 & 38.1 & 224 & 45.6 & 0.20 & 4.6 \\
\hline 33.5 & 112 & 33.4 & 0.28 & 5.2 & 31.8 & 128 & 31.8 & 0.25 & 4.6 \\
\hline 26.7 & 61.5 & 21.1 & 0.35 & 5.2 & 25.4 & 65.5 & 20 & 0.31 & 4.6 \\
\hline 23.8 & 43 & 16.9 & 0.39 & 5.2 & 22.2 & 43.5 & 15.5 & 0.36 & 4.6 \\
\hline 20.1 & 25.8 & 12.1 & 0.47 & 5.2 & 19.1 & 27.3 & 11.5 & 0.42 & 4.6 \\
\hline
\end{tabular}

RGM sizes were intentionally selected for the Bond mill tests such that they have both lower mass and greater surface area. The research objective was to show that surface area is the main factor for the higher grinding efficiency of RGM instead of the total mass. Table 2 shows selected mill charges with the same number of grinding elements.

Table 2. Bond mill test media charge $-5 \%$ greater surface area.

\begin{tabular}{|c|c|c|c|c|c|c|c|}
\hline $\begin{array}{l}\text { Ball Diameter/Relo } \\
\text { Edge Arc, }[\mathrm{mm}]\end{array}$ & $38.10 / 40.2$ & $31.8 / 33.4$ & $25.4 / 26.7$ & $22.2 / 23.8$ & $19.05 / 20.1$ & Total Number & Total Mass, $\mathrm{g}$ \\
\hline $\begin{array}{l}\text { Ball Charge-number } \\
\text { of balls }\end{array}$ & 25 & 39 & 62 & 69 & 90 & 285 & 20,115 \\
\hline $\begin{array}{l}\text { RGM Charge-number } \\
\text { of relos }\end{array}$ & 25 & 39 & 62 & 69 & 90 & 285 & 19,149 \\
\hline
\end{tabular}

\section{Materials and Methods}

This research's main goal was to collect and analyze data from comparative laboratory grinding tests to compare the grinding performance of RGM with a conventional ball charge in a Bond ball mill (BICO BRAUN, Burbank, CA, USA). The tests are discussed in more detail below.

\subsection{Media Charge Conditions}

Three media conditions were considered to have comparable and repeatable results:

- Media mass,

- Media surface area, and

- Media size distributions. 
For the comparative tests, the standard Bond ball charge was set as the base case. The RGM charge was controlled to match two of the three media conditions of the balls, with the third one being different (surface area), to distinguish one effect in each test. Table 2 presents the details of both media charge size distributions.

Ball charge (Table 2) is the standard Bond ball mill charge condition, which was used as the base case for comparison. RGM charge (Table 2) was defined to ensure that the RGM have a similar size but significantly smaller mass. Table 3 presents an RGM charge in which six smaller Relo grinding bodies $(26.7 \mathrm{~mm})$ were omitted, and six larger grinding Relo bodies were added to give equal mass to the balls. This RGM charge has a similar mean size and mass in each size fraction (hence the total mass), but due to their shape, there is approximately $10 \%$ more surface area than that of balls.

Table 3. Bond mill media charge-equal total mass, 10\% greater surface area.

\begin{tabular}{ccccccccc}
\hline $\begin{array}{c}\text { Ball Diameter/Relo } \\
\text { Edge Arc [mm] }\end{array}$ & $\mathbf{4 0 / 4 1 . 4}$ & $\mathbf{3 8 . 1 0 / 4 0 . 2}$ & $\mathbf{3 1 . 8 / 3 3 . 4}$ & $\mathbf{2 5 . 4 / 2 6 . 7}$ & $\mathbf{2 2 . 2 / 2 3 . 8}$ & $\mathbf{1 9 . 0 5 / 2 0 . 1}$ & Total Number & Total Mass [g] \\
\hline Number of balls & 0 & 25 & 39 & 62 & 69 & 90 & 285 & 20,115 \\
\hline Number of RGM & 6 & 25 & 39 & 56 & 69 & 90 & 285 & 20,165 \\
\hline
\end{tabular}

\subsection{Ore Sample}

The sample selected was a pegmatite, which is a spodumene ore. XRF results are shown in Table 4, and the feed particle size distribution (PSD) is shown in Table 5. It was composed primarily of quartz and plagioclase, with minor amounts of lepidolite, beryl, and potassium feldspar. The ore sample was rather hard rock, with $w_{i}=16.8 \mathrm{kWh} / \mathrm{t}$, and was prepared using a jaw crusher and a rotary divider to obtain the representative subsamples for each test.

Table 4. Feed chemical analysis (L.O.I. = lost on ignition).

\begin{tabular}{ccccccccc}
\hline Element & $\mathrm{SiO}_{2}$ & $\mathrm{Al}_{2} \mathbf{O}_{3}$ & $\mathrm{Na}_{2} \mathbf{O}$ & $\mathrm{Li}_{2} \mathbf{O}$ & $\mathbf{K}_{2} \mathbf{O}$ & $\mathbf{F e}_{2} \mathbf{O}_{3}$ & $\mathrm{CaO}$ & L.O.I. \\
\hline$(\%)$ & 72.16 & 17.68 & 6.56 & 1.20 & 0.92 & 0.50 & 0.09 & 0.89 \\
\hline
\end{tabular}

Table 5. Particle-size distribution analysis.

\begin{tabular}{ccccccccccccc}
\hline Size $(\boldsymbol{\mu m})$ & $\mathbf{3 3 5 0}$ & $\mathbf{2 0 0 0}$ & $\mathbf{1 5 0 0}$ & $\mathbf{1 0 0 0}$ & $\mathbf{8 0 0}$ & $\mathbf{6 0 0}$ & $\mathbf{4 0 0}$ & $\mathbf{3 0 0}$ & $\mathbf{2 0 0}$ & $\mathbf{1 5 0}$ & $\mathbf{1 0 0}$ & $\mathbf{7 5}$ \\
\hline Cum. Passing $(\%)$ & 100.00 & 98.69 & 88.42 & 66.93 & 49.66 & 38.19 & 28.12 & 20.77 & 14.37 & 9.44 & 4.66 & 1.14 \\
\hline
\end{tabular}

\subsection{Power Draw Measurement}

To compare the power draw required by the Bond mill in the grinding process with RGM versus balls, the active power consumption (watts) of the electric motor driving the mill was measured. This assumption is based on the fact that no significant differences can be found between both grinding media for the electric and mechanical losses of the motor, and, consequently, the measurement of the active power can be used to compare the mechanical power draw.

The electric driving machine is a single-phase motor, so to evaluate its electric consumption, a measurement of the supply voltage and current is needed. Then, the active power is obtained according to:

$$
P=\frac{1}{T} \int_{0}^{T} v(t) i(t) d t
$$

with $P$ the active power, $T$ the period, $v(t)$ the instantaneous value of the supply voltage, and $i(t)$ the instantaneous value of the supply current. A differential probe with $\times 500$ attenuation was used for voltage signal measuring. In the case of the current signal, a 
probe providing a transformation of $100 \mathrm{mV} / \mathrm{A}$ was used. Both signals were recorded and processed employing a $60 \mathrm{MHz}$ bandwidth digital scope.

\subsection{Test Procedure}

The Bond work index, $w_{i}$, is in everyday use for the assessment of comminution efficiency, and it has been generally accepted as a measure of material grindability (ores, cement clinker). In this research, the Bond test procedure was considered fundamental for comparing the milling performance of different grinding media shapes. However, as some authors noted [22], there is a problem in designing a locked-cycle test procedure for such a purpose since the Bond test does not take the actual energy usage into account. The standard Bond test procedure $[2,23]$ requires stopping the test when the grindability reaches equilibrium, which is typically achieved at $3 \%$ variation between the last two runs. Since the RGM charge may require fewer mill revolutions than the ball charge, this indicates that the grinding time in the two tests would be different. Thus, the energy input for the ball charge test would be greater than for the RGM charge test.

With the aim of predicting the grinding performance of RGM in a full-scale ball mill, a simplified procedure for the scale-up of a ball mill was adopted. This procedure involved laboratory tests using the Bond ball mill and test conditions to simulate the full-scale mill circuit's steady-state performance from laboratory results. Accordingly, all the locked-cycle laboratory tests were conducted in a standard Bond ball mill loaded with two types of steel grinding media — balls and RGM — to treat the same feed ore at a time.

Two types of comparative locked-cycle tests were conducted:

- Test series 1: Standard Bond work index tests using the standard set of balls and RGM charge (Table 2).

- $\quad$ Test series 2: Comparative grinding tests using balls and RGM at equal mass and media size distribution (Table 3) but at different circulating loads.

The test procedure for the first series of grinding tests follows the well-known Bond ball mill grindability test $[2,23]$ precisely. In the Bond ball milling test, a locked-cycle test, the fresh feed to the test is crushed down to $100 \%$ under $3.35 \mathrm{~mm}$. The mill grinds a constant $700 \mathrm{~mL}$ of ore. After each grind, the mill contents are screened to remove undersize and replenished with an equal mass of new feed. The length of grinding time for each run is adjusted until the oversize fraction's mass is consistently 2.5 times greater than the undersize. Under these conditions, the test approximates a closed-circuit continuous mill's steady-state performance with a circulating load of $250 \%$.

The second series of locked-cycle grinding tests were run at four different circulating loads of $100 \%, 150 \%, 250 \%$, and $350 \%$. Since the RGM charge required fewer mill revolutions than the ball charge [24], a slight change in the methodology was needed to get a better comparative analysis. The modification consisted of adding more fresh feed to the tests using RGM to get the same circulating load (250\%) at the same number of mill revolutions of both ball charge and RGM charge tests. To compensate for the lower circulating load when RGM was used, the amount of fresh sample was increased at the same number of revolutions as per the standard tests with balls. The test conditions for both locked-cycle tests are summarized in Table 5 . Since the grindability index (net grams of screen undersized product per mill revolution, Gpr) is the primary variable to determine the Bond work index [2], it was used as a comparative measurement to show the difference between RGM charge and ball charge milling performance.

\section{Results and Discussion}

\subsection{Power Draw Measurements}

Since the bulk density of an RGM charge was approximately 10\% higher than the bulk density of a ball charge, the two media charges' torques should be different. Therefore, it was logical to expect that there must be a difference in the power draw of these two types of grinding media. According to Lameck's results [17], cylpebs draw approximately 30\% 
less power than balls at $90 \%$ of critical speed (Figure 2), so it was interesting to carry out a similar comparative study between RGM and balls.

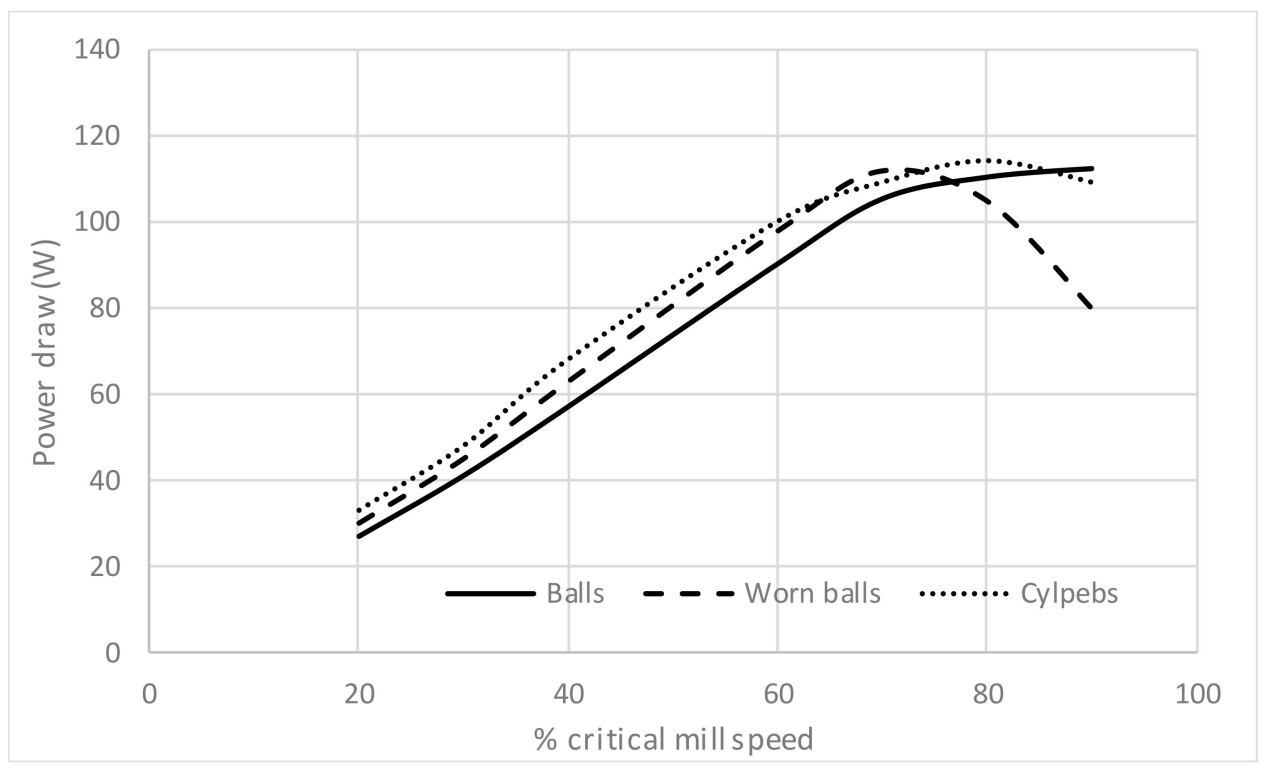

Figure 2. Power variation with mill speed for different media shapes (adapted from [16]).

Measurements performed (see Table 6) confirmed that RGM bodies draw higher power than balls without mineral charge, similar power as balls at standard conditions of a Bond test (35\% of voids within the ball charge filled with mineral charge), and less power than balls. It is important to note that RGM and balls may draw the same power at a given $\%$ of critical speed, but grindability might not be equal. These grinding tests were performed for $2 \mathrm{~min}$, the power draw deviation in all cases being below 1.5\%.

Table 6. Power draw measurements in a Bond ball mill.

\begin{tabular}{cccc}
\hline Bond Mill Charge & $\begin{array}{c}\text { Power Draw without Ore } \\
\text { Sample }[W]\end{array}$ & $\begin{array}{c}\text { Power Draw at 35\% of Voids } \\
\text { within the Ball Charge [W] }\end{array}$ & $\begin{array}{c}\text { Power Draw, at 100\% of Voids } \\
\text { within the Ball Charge [W] }\end{array}$ \\
\hline No load & 309 & - & - \\
Standard ball charge $(20.1 \mathrm{~kg})$ & 402 & 437 & 462 \\
RGM charge $(20.1 \mathrm{~kg})$ & 424 & 440 & 445 \\
\hline
\end{tabular}

Considering that the Bond methodology uses a filling ratio in the standard test ball mill (35\%), which is relatively lower than the filling ratio at industrial scale (where the ideal situation is when the mineral charge fills $100 \%$ of voids), and considering that the influence of mineral filling ratio is clearly stronger in the case of balls than in the case of RGM charge, it could be expected that the Bond methodology would overestimate the specific energy consumption in the case of using RGM charge. Further research should be performed to define a coefficient that lets an RGM work index be obtained from standard Bond tests.

\subsection{Test Series 1}

The main goal of test series 1 was to see whether the lower mass (5\% lower) of the RGM charge would affect the grinding performance and calculation of $w_{i}$. The RGM charge was designed to have a $5 \%$ lower total weight but a $5 \%$ higher total surface area. In both cases, $w_{i}$ values were calculated using the formula proposed by Bond in the standard test (Equation (2)).

$$
w_{i}[k W h / s h t]=\frac{44.5}{P_{100}^{0.23} \cdot G p r^{0.82} \cdot\left(\frac{10}{\sqrt{P_{80}}}-\frac{10}{\sqrt{F_{80}}}\right)}
$$


Tests results are summarized in Table 7. Standard tests have shown that the RGM charge achieves a $2 \%$ lower $w_{i}$ than balls at equal testing conditions (number of revolutions, mill speed, ore sample, closing screen aperture). This result cannot be considered conclusive, for it is widely accepted [5] that the repeatability error of the standard Bond test is around 3.5\%. However, it must be taken into account that the RGM charge was 5\% lighter than the ball charge when applying Bond's methodology to RGM.

Table 7. Standard Bond grindability tests parameters and results (Test series 1).

\begin{tabular}{cccc}
\hline Test Parameter & Unit & Balls & RGM \\
\hline Weight of media charge & $(\mathrm{kg})$ & 20.123 & 19.145 \\
$\mathrm{P}_{100}$ & (microns) & 106 & 106 \\
$\mathrm{Gpr}$ & $(\mathrm{g} / \mathrm{rev})$ & 1.201 & 1.190 \\
$\mathrm{~F}_{80}$ & $($ microns $)$ & 2044 & 2044 \\
$\mathrm{P}_{80}$ & $($ microns $)$ & 84 & 81 \\
\hline Result & Unit & Balls & RGM \\
\hline$w_{i}$ & $(\mathrm{kWh} / \mathrm{t})$ & 16.62 & 16.30 \\
\hline
\end{tabular}

Moreover, if a similar work index is obtained using a 5\% lighter steel charge, this means that less grinding charge weight can produce similar grinding work, so a better energy conversion is produced when using RGM charges.

\subsection{Test Series 2}

It is widely accepted that the higher the circulating load of a grinding circuit is, the lower the probability of ultrafine particle production. It means that the most efficient ball milling circuits require a high circulating load ratio (CLR) [16]. By maintaining a high percentage of coarse solids in the mill, a high circulating load results in a much more efficient grinding circuit. The purpose of our grinding tests at various circulating loads was to see how this could apply to new grinding media compared to standard grinding media. These tests clearly show the advantages of RGM over balls at different circulating loads (Figure 3).

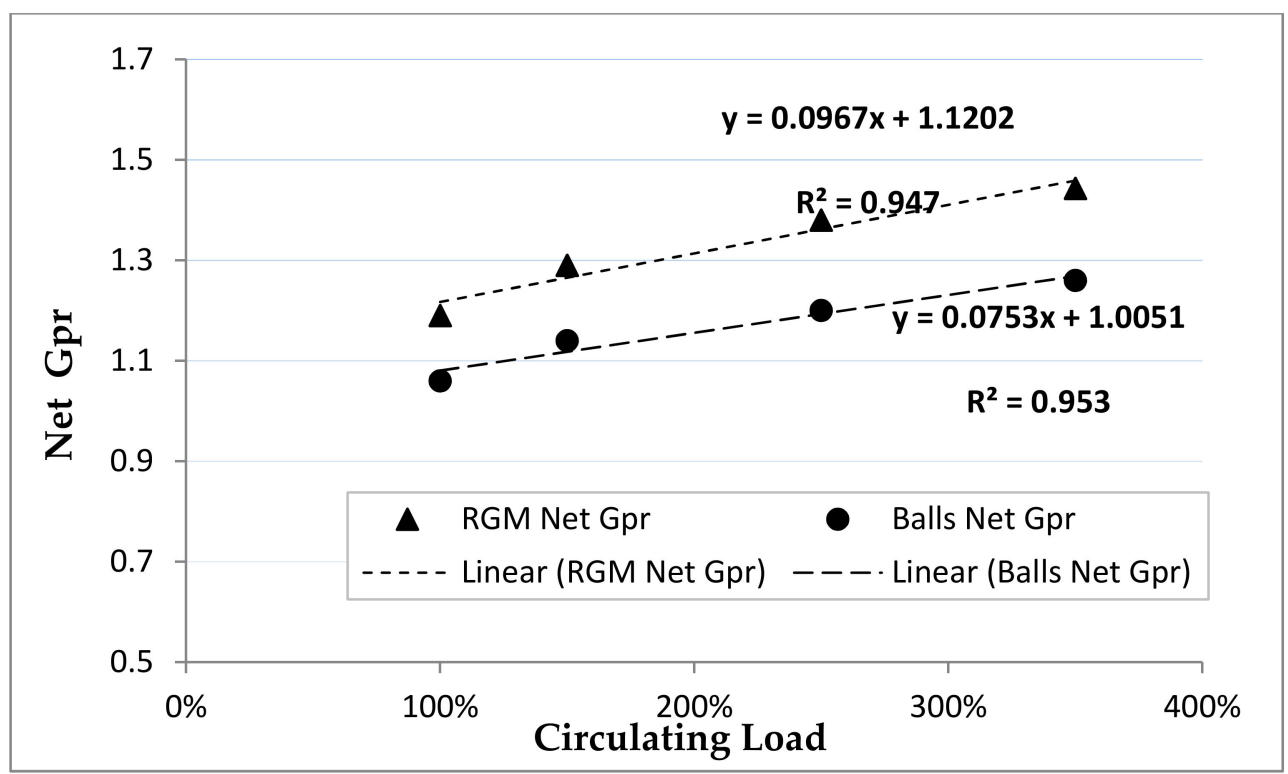

Figure 3. Grinding tests at different CLR-Net Gpr vs. CLR.

The results show that, using RGM, the most efficient ball milling circuits may not necessarily require a high circulating load ratio. The data revealed that the RGM at 
$100 \%$ circulating load and balls at $250 \%$ circulating load have almost equal productivity (grinding rate), which means that the RGM charge is more energy-efficient and will require considerably less power for classification (cyclone feed pumping). McIvor $[25,26]$ wrote that $250 \%$ circulating load pumping accounts for about $8 \%$ of total grinding costs. Therefore, the replacement of balls with RGM will reduce total grinding costs at the same level of mill productivity.

On the other hand, if energy consumption is kept equal, the RGM charge achieves on average $14 \%$ higher productivity (measured in Gpr) than balls at the corresponding circulating load.

As previously discussed, these four pairs of tests at different CLRs were performed in a Bond mill. The mass of two mill charges and the number of revolutions per given circulating load was equal, and mill speed was kept constant (the one in the standard test mill, $70 \mathrm{rpm}$ ). More feed was added to the Relo tests to reach the steady state (desired circulating load) due to the Relo media's apparent higher grinding kinetics.

The results from these tests were studied using linear regression equations (Figures 3 and 4). In Figure 3, the circulating load ratio (\%) is represented in abscises while net Gpr is represented in ordinates. This linear regression model shows that, if circulating load is increased by $1 \%$, then the net Gpr of a mill loaded with RGM will be expected to increase by 0.097 $\mathrm{g} / \mathrm{rev}$, and if there were no circulating load, we would expect a net Gpr of $1.12 \mathrm{~g} / \mathrm{rev}$. For balls, net Gpr will be expected to increase by $0.075 \mathrm{~g} / \mathrm{rev}$ if the circulating load is increased by $1 \%$; with no circulating load, the ball mill's net Gpr should be $1 \mathrm{~g} / \mathrm{rev}$. Moreover, comparing the situation at high circulating loads (350\%), RGM net Gpr is $26 \%$ higher than ball Net Gpr, which means that, under similar conditions, a mill throughput should increase by that percentage when grinding with a RGM charge. This difference can be even greater at industrial scale, since for the same fraction of the critical speed, a full-scale mill's rotational speed is lower than that of a pilot-scale mill [24]. Thus, the breakage rate of a full-scale mill is higher at the smaller sizes because there are more grinding media layers present in the bulk of the charge in full-scale mills [24]. McIvor [25,26] pointed out that the material's size distribution going through the ball mill was much coarser at a high CLR than at a low CLR.

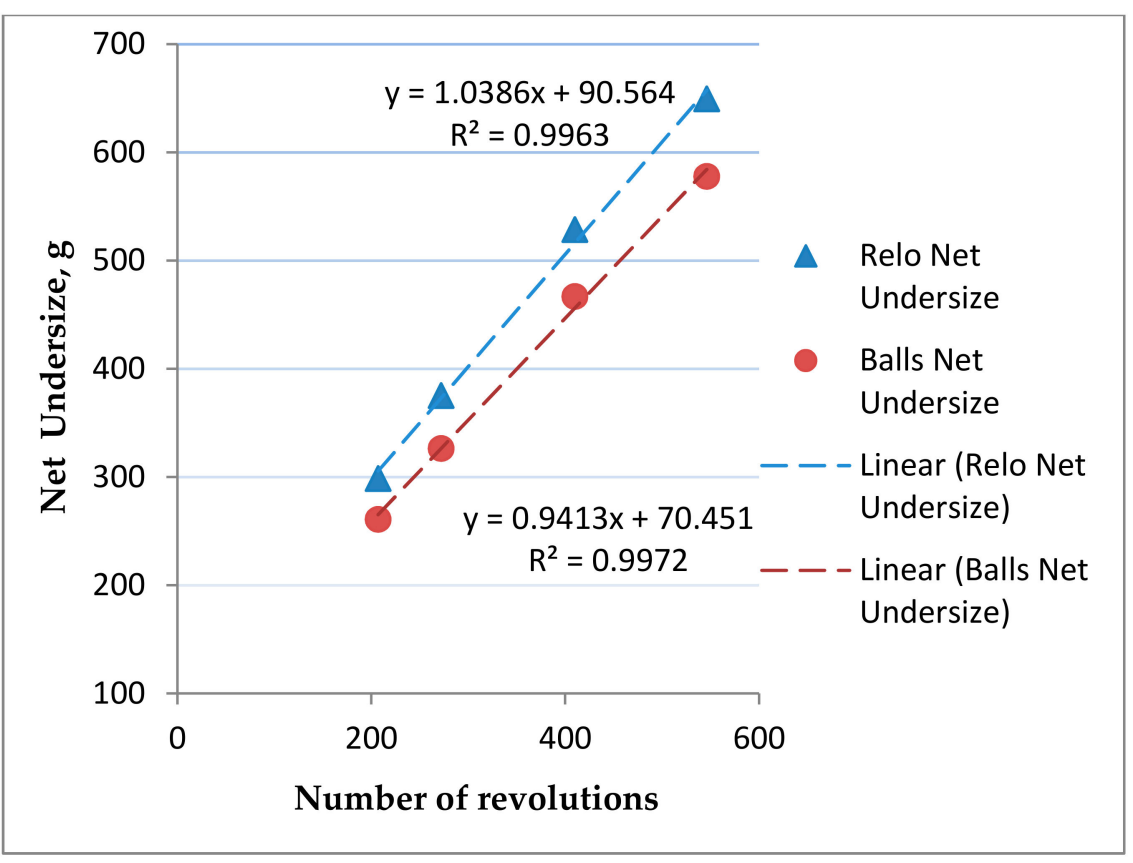

Figure 4. Grinding tests at different CLR—net undersize vs. number of revolutions.

In Figure 4, the number of revolutions versus the net undersize is plotted. The linear regression model shows that, at a large number of mill revolutions (longer grinding cycles, 
higher residence time), the net undersize of Relo grinding media will be approximately $10.5 \%$ higher than the net undersize of balls. So when the circulating load is zero, the RGM charge productivity is $10-12 \%$ higher.

The higher fine-particle production with the RGM charge corresponds perfectly with the contact spots ratio between two Relo bodies and two spheres. According to Penchev [22], a $40 \mathrm{~mm}$ radius sphere would have the same weight as a Reuleaux spheroidal tetrahedron with spherical wall $87 \mathrm{~mm}$ in radius; and the contact area between two Relo grinding bodies will be $29 \%$ larger than between two balls. Hence, the probability of collisions of RGM with an ore particle will be $29 \%$ higher than in balls.

\subsection{Optimum Economic Circulating Ratio (Trade-Off between RGM and Balls at Circulating Loads)}

Increasing pumping energy (pump and cyclone maintenance costs included) should be balanced against decreasing grinding energy and media costs when circulating load increases, so the optimum economic circulating load can be identified (Table 8).

Table 8. Trade-off between ball charge and RGM charge in terms of circulating load.

\begin{tabular}{|c|c|c|c|c|c|}
\hline Media & $\begin{array}{l}\text { Mill Throughput } \\
\text { [tph] }\end{array}$ & CLR [\%] & $\begin{array}{l}\text { Relative Grinding } \\
\text { Costs }[\%]\end{array}$ & $\begin{array}{c}\text { Relative Pumping/Classification } \\
\text { Costs }[\%]\end{array}$ & Total [\%] \\
\hline \multicolumn{6}{|c|}{ Base case } \\
\hline Balls & 100 & 245 & 92 & 8 & 100 \\
\hline Relo & 100 & 100 & 92 & 4 & 96 \\
\hline \multicolumn{6}{|c|}{ Increased by $14 \%$} \\
\hline Balls & 114 & 558 & 84 & 16 & 100 \\
\hline Relo & 114 & 245 & 84 & 8 & 92 \\
\hline
\end{tabular}

If the RGM mill charge and the ball mill charge draw the same power of the mill motor and have equal mill throughput (100 tph), the grinding circuit operating costs with RGM charge should be $4 \%$ lower (Table 8 ), mainly due to the lower circulating load of the RGM circuit. However, under a $14 \%$ production increase scenario, the CLR should increase from $245 \%$ to $558 \%$, thus increasing pumping/classification costs and increasing total operating costs up to $8 \%$.

\subsection{Correction Coefficients for Bond WI Using RGM}

Finally, looking at the interpretation of these laboratory test results, we may conclude that RGM behavior and milling performance are very different in an industrial mill than in a laboratory scale [21]. Plant test results show drastically lower energy consumption $(\mathrm{kWh} / \mathrm{t})$ of RGM than laboratory test data suggest. The explanation can be found by looking at the difference between breakage rate distributions obtained from the pilot-scale tests and full-scale mills [27]. Yu [28] wrote that, for the same fraction of the critical speed, a full-scale mill's rotational speed is lower than that of a laboratory-scale mill. Thus, at the coarse sizes, the breakage rates in a laboratory-scale mill are higher than that in a full-scale mill. A full-scale mill's breakage rate is higher at the smaller sizes because there are more grinding media layers present in the bulk of the charge in full-scale mills. These laboratory grinding tests with RGM may not be directly used to predict a RGM-loaded full-scale mill.

A new model is needed to describe an industrial tumbling mill charged with RGM, and it is required to introduce a correction factor to apply Bond's methodology. It is important to consider that a reduction in the Bond work index, maintaining the rest of the conditions, would reduce the circulating load, increase the fresh feed throughput to the closed grinding circuit and eventually increase grinding production. Based on this test program, we can conclude that higher net undersize will reduce $w_{i}$ by a certain percentage. The lower power draw of RGM charge and reduced $w_{i}$ by RGM mean that the total reduction of the standard Bond $w_{i}$ will need to be justified by correction coefficients. 
Using this interdependence, we show that RGM will yield higher throughput than balls at similar grind size at the same power draw. The advantage of the higher efficiency could be achieved in different ways:

- $\quad$ By maintaining current throughput with a smaller grinding size (i.e., when the liberation size decreases);

- $\quad$ By increasing throughput, maintaining the grinding size;

- $\quad$ By reducing the filling ratio of the ball mill, thus lowering power and grinding media consumption.

\section{Conclusions}

- Power measurement tests evidenced differences in RGM and ball energy performance. Further research should be carried out to define a coefficient to obtain an RGM work index from standard Bond tests.

- Standard Bond tests did not show a clear improvement in the energy efficiency of the RGM charge compared to balls. The Bond ball work index using the RGM charge was $2 \%$ lower, while the repeatability error for the standard Bond test is estimated to be below $3.5 \%$.

- Grinding tests at various CLRs and the same grinding time at each other circulating load test revealed that the grinding rate of the RGM charge at $100 \%$ circulating load is the same as the grinding rate of balls at $250 \%$ of circulating load.

- Linear regression calculations suggested that, at a low number of mill revolutions (equal to high circulating load conditions), RGM need 50\% less grinding time than balls to produce the same amount of undersize. It showed that, working at coarser feed (high circulating loads), RGM could be more efficient than balls, thus lowering the power consumption of tumbling mills. The mass of undersize products from these tests was $14 \%$ higher on average when the RGM charge was used.

- The trade-off carried out between RGM and balls at circulating loads showed a significant improvement in energy efficiency if using RGM when facing a throughput increase, mainly due to the reduction in operating costs.

Author Contributions: Conceptualization, N.K. and J.M.M.-A.; methodology, N.K., B.S. and J.M.M.A.; validation, P.B. and V.G.; formal analysis, N.K. and J.M.M.-A.; investigation, B.S. and M.G.M.; resources, N.K., B.S. and J.M.M.-A.; data curation, N.K.; writing-original draft preparation, N.K.; writing-review and editing, B.S., J.M.M.-A. and M.G.M.; visualization, N.K., P.B. and V.G.; supervision, P.B. and V.G.; funding acquisition, N.K. and M.G.M. All authors have read and agreed to the published version of the manuscript.

Funding: This research was partially funded by the Spanish Ministry of Economy and Competitiveness, under project DPI2017-83804-R.

Institutional Review Board Statement: Not applicable.

Informed Consent Statement: Not applicable.

Data Availability Statement: Not applicable.

Acknowledgments: Wardell Armstrong International Ltd. is gratefully acknowledged for performing the required laboratory test work. Authors also thank Donald Leroux and Ahmad Hassanzadeh for their comments and advice regarding RGM performance.

Conflicts of Interest: The authors declare no conflict of interest.

\section{References}

1. Jankovic, A.; Valery, W.; La Rosa, D. Fine Grinding in the Australian Mining Industry. In Proceedings of the 3rd International Conference on Recent Advances in Materials, Minerals and Environment (RAMM 2003), Nibong Tebal, Malaysia, January 2003; Universiti Sains Malaysia: Penang, Malaysia.

2. Bond, F.C. Crushing and Grinding Calculations Parts 1 and 2. Br. Chem. Eng. 1961, 6, 378-385, 543-548. 
3. Pedrayes, F.; Norniella, J.G.; Melero, M.G.; Menéndez-Aguado, J.M.; del Coz-Díaz, J.J. Frequency domain characterization of torque in tumbling ball mills using DEM modelling: Application to filling level monitoring. Powder Technol. 2018, 323, 433-444. [CrossRef]

4. Osorio, A.M.; Menéndez-Aguado, J.M.; Bustamante, O.; Restrepo, G.M. Fine grinding size distribution analysis using the Swebrec function. Powder Technol. 2014, 258, 206-208. [CrossRef]

5. Rodríguez, B.Á.; García, G.G.; Coello-Velázquez, A.L.; Menéndez-Aguado, J.M. Product size distribution function influence on interpolation calculations in the Bond ball mill grindability test. Int. J. Miner. Process. 2016, 157, 16-20. [CrossRef]

6. Ciribeni, V.; Bertero, R.; Tello, A.; Puerta, M.; Avellá, E.; Paez, M.; Menéndez Aguado, J.M. Application of the Cumulative Kinetic Model in the Comminution of Critical Metal Ores. Metals 2020, 10, 925. [CrossRef]

7. Ballantyne, G.R.; Powell, M.S.; Tiang, M. Proportion of Energy Attributable to Comminution. In Proceedings of the 11th AusIMM Mill Operator's Conference, Hobart, Australia, 29-31 October 2012.

8. Radziszewski, P. Energy recovery potential in comminution processes. Miner. Eng. 2013, 46-47, 83-88. [CrossRef]

9. Bouchard, J.; LeBlanc, G.; Levesque, M.; Radziszewski, P.; Georges-Filteau, D. Breaking Down Energy Consumption in Industry Grinding Mills. In Proceedings of the 49th Annual Canadian Minerals Processors Conference, Ottawa, ON, Canada, 17-19 January 2017; Muinonen, J., Cameron, R., Zinck, J., Eds.; Canadian Institute of Mining, Metallurgy and Petroleum (CIM): Westmount, QC, Canada, 2017; pp. 25-35.

10. Hassanzadeh, A. The Effect of Make-Up Ball Size Regime on Grinding Efficiency of Full-Scale Ball Mill. In Proceedings of the XVII Balkan Mineral Processing Congress, Antaliya, Turkey, 1-3 November 2017; Volume 1, pp. 117-124.

11. Simba, K.P.; Moys, M. Effects of mixtures of grinding media of different shapes on milling kinetics. Miner. Eng. 2014, 61, 40-46. [CrossRef]

12. Norris, G.C. Some grinding tests with spheres and other shapes. Trans. Inst. Miner. Metall. 1954, 63, $197-209$.

13. Kelsall, D.F.; Stewart, P.S.B.; Weller, K.R. Continuous grinding in a small wet ball mill Part 5. A study of the influence of media shape. Powder Technol. 1973, 8, 77-83. [CrossRef]

14. Cloos, U. Cylpebs: An alternative to balls as grinding media. World Min. 1983, 36, 59.

15. Herbst, J.A.; Lo, Y.C. Grinding efficiency with balls or cones as media. Int. J. Miner. Process. 1989, 26, 141-151. [CrossRef]

16. Shi, F. Comparison of grinding media-Cylpebs versus balls. Miner. Eng. 2004, 17, 1259-1268. [CrossRef]

17. Lameck, N.N.S. Effects of Grinding Media Shapes on Ball Mill Performance. Master's Thesis, Faculty of Engineering and The Built Environment, University of the Witwatersrand, Johannesburg, South Africa, 2006.

18. Ipek, H. Effects of grinding media shapes on breakage parameters. Part. Part. Syst. Charact. 2007, 24, 229-235. [CrossRef]

19. Cuhadaroglu, D.; Samanli, S.; Kizgut, S. The effect of grinding media shape on the specific rate of breakage. Part. Part. Syst. Charact. 2008, 25, 465-473. [CrossRef]

20. Simba, K.P. Effects of Mixture of Grinding Media of Different Shapes on Milling Kinetics. Ph.D. Thesis, Faculty of Engineering and the Built Environment, University of the Witwatersrand, Johannesburg, South Africa, 2010. Available online: https: / / core.ac.uk/download/pdf/39669573.pdf (accessed on 20 April 2021).

21. Bodurov, P.; Genchev, V. Industrial tests with innovative energy saving grinding bodies. J. Multidiscip. Eng. Sci. Technol. JMEST 2017, 4, 6498-6503.

22. Penchev, T.; Bodurov, P. Comparative Analysis of the Parameters of Spherical and Relo Body Balls for Drum Mills. In Proceedings of the International Conference on Mining, Material and Metallurgical Engineering, Prague, Czech Republic, 11-12 August 2014. Paper No. 144.

23. Coello Velázquez, A.L.; Menéndez-Aguado, J.M.; Brown, R.L. Grindability of lateritic nickel ores in Cuba. Powder Technol. 2008, 182, 113-115. [CrossRef]

24. Genchev, V.; Bodurov, P.; Kolev, N.; Leroux, D.P. Assessing the Response of Tumbling Mills to the Replacement of Balls by Relo Grinding Media (RGM)-Part 1. Comparative Bench-Scale Experiments and Demonstration Full-Scale Test. In Proceedings of the 52nd Annual Canadian Mineral Processors Operators Conference, Ottawa, ON, Canada, 21-23 January 2020.

25. McIvor, R.E. Why do we need such a high recirculating load on our ball mill? Metcomtech Grinding Bulletin Issue 4, February 2013. Available online: https:/ / www.metcomtech.com/grindingbulletin4.php (accessed on 20 April 2021).

26. McIvor, R.E. Plant performance improvements using grinding circuit Classification system efficiency. Min. Eng. 2014, 66, 67-71.

27. Morrell, S. A new autogenous and semi-autogenous mill model for scale-up, design and optimisation. Miner. Eng. 2004, 17, 437-445. [CrossRef]

28. Yu, P. A Generic Dynamic Model Structure for Tumbling Mills. Ph.D. Thesis, The University of Queensland, Queensland, Australia, 2014. 